\title{
Successful pregnancy in a patient with Ebstein's anomaly: a case report and review of literature
}

\author{
Charu Sharma $^{1}$, Shiv Shankar Singh ${ }^{2}$, M. K. Saha ${ }^{1}$, Bhabani Pegu ${ }^{1}$
}

\begin{abstract}
${ }^{1}$ Department of Obstetrics \& Gynecology, Andaman \& Nicobar Islands Institute of Medical Sciences, Port Blair, India ${ }^{2}$ Department of Medicine, Andaman \& Nicobar Islands Institute of Medical Sciences, Port Blair, India
\end{abstract}

Received: 30 December 2015

Accepted: 06 February 2016

\author{
*Correspondence: \\ Dr. Charu Sharma, \\ E-mail: sharma.charu651@gmail.com
}

Copyright: (C) the author(s), publisher and licensee Medip Academy. This is an open-access article distributed under the terms of the Creative Commons Attribution Non-Commercial License, which permits unrestricted non-commercial use, distribution, and reproduction in any medium, provided the original work is properly cited.

\begin{abstract}
Ebstein's anomaly, a rare congenital heart disease, has an extremely variable natural history, depending on variety of pathological features. We here describe a case of a patient with Ebstein's anomaly who had an uneventful vaginal delivery of a healthy term baby. The anomaly was diagnosed during childhood, was not associated with other cardiac anomalies, cyanosis or pre-excitation and the echocardiographic degree of severity was low.
\end{abstract}

Keywords: Ebstein's anomaly, Atrial septal defect, Pregnancy, Echocardiography, Tricuspid valve

\section{INTRODUCTION}

Ebstein's anomaly (EA), first described by Wilhelm Ebstein in 1866 in a 19 year old man who died shortly after presenting with cyanosis, dyspnoea, palpitations and heart failure, is a rare congenital defect occurring in 1 in 20,000 live births. ${ }^{1,2}$ It is characterized by the apical displacement of the septal and posterior leaflets of the tricuspid valve resulting in reduction in the size of the right ventricle and atrialization of the upper part of the right ventricle that behaves functionally as a part of the right atrium. These patients have severe tricuspid insufficiency which contributes to the enlargement of the right atria. $^{2}$

Pregnancy however is well tolerated and the maternal risks of pregnancy co-relates well with the degree of tricuspid regurgitation, right ventricular function and presence of cyanosis. We here report a case of successful outcome of pregnancy in Ebstein's anomaly.

\section{CASE REPORT}

A 20 years old female, $G_{1}$ with history of Ebstein's anomaly, diagnosed at early childhood, presented to our labor ward at 40 weeks of gestation with labor pains. During her antenatal period she was admitted twice in the hospital in view of threatened abortion at eight weeks period of gestation and for preterm labor pains at 32 weeks. She was managed conservatively both the times. She had mild dyspnoea and palpitations in the third trimester but she remained in NYHA class I throughout her pregnancy. There was no history of recurrent chest infections, cyanosis or heart failure in the past and no significant family history. We followed her by regular echocardiography and allowed her to go for spontaneous onset of labor.

She presented to us at 40 weeks of gestation with labor pains. Physical examination revealed blood pressure of $124 / 80 \mathrm{~mm} \mathrm{Hg}$; heart rate of $80 \mathrm{bpm}$, body mass index (BMI) was $22.2 \mathrm{~kg} / \mathrm{m}^{2}$. Her oxygen saturation $\left(\mathrm{SpO}_{2}\right)$ at 
room air was $98 \%$. Liver was not palpable and there were no other signs of heart failure and cyanosis. On auscultation a pansystolic murmur was heard in the tricuspid area. Blood reports were within normal limits. Ultrasonography at 36weeks was normal and expected fetal weight was 2910gms+/-200gms. Electrocardiogram (ECG) demonstrated Sinus rhythm at $74 \mathrm{bpm}$ with incomplete right bundle branch block (Figure 1).

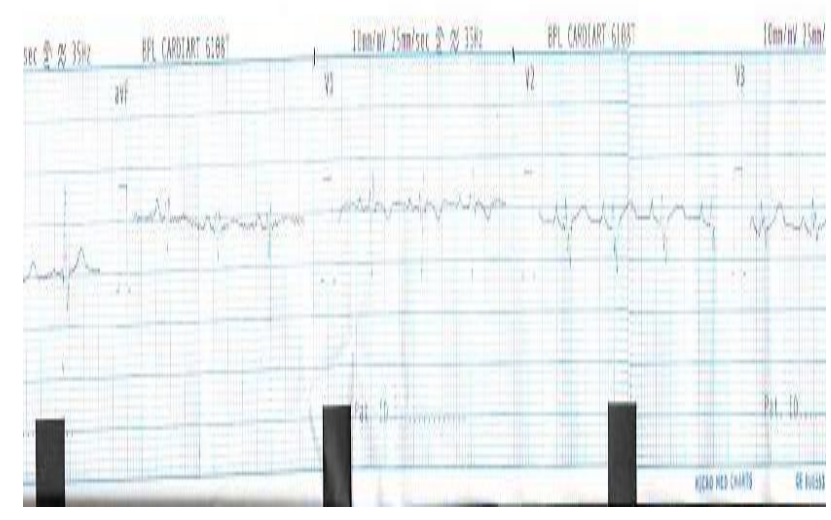

Figure 1: ECG: Right bundle branch block pattern in V1 lead.

Trans-thoracic echocardiogram (TTE) showed typical signs of Ebstein's anomaly i.e. septal leaflet of tricuspid valve was tethered to inter-ventricular septum, inferior displacement of tricuspid valve; moderate tricuspid regurgitation (TR) with peak gradient (PG) of 22.84 $\mathrm{mmHg}$, dilated right atrium and right ventricle, interatrial septum was thin with no shunt. Ejection fraction was $55 \%$ and there was no clot or vegetation (Figure $2-$ $4)$.

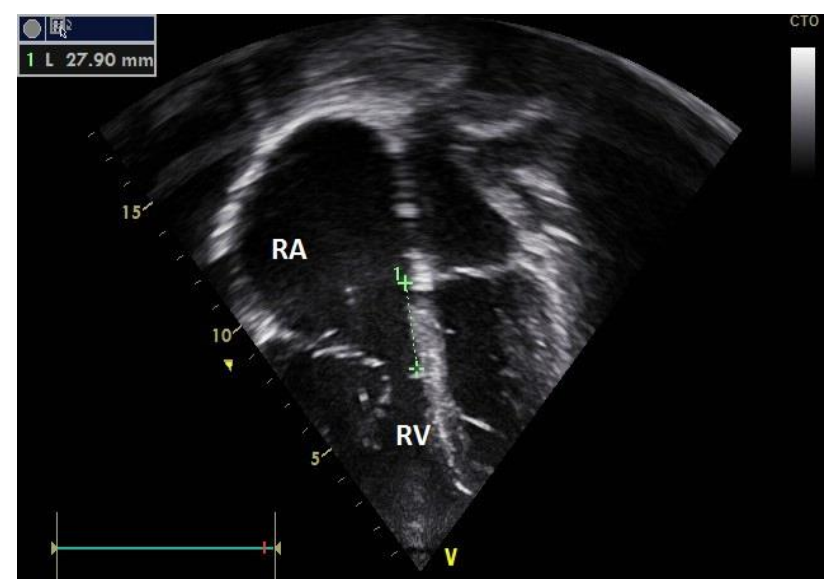

Figure 2: Echocardiography: Four chamber view. Apical displacement of the septal leaflet of tricuspid valve $(27.9 \mathrm{~mm})$. RA (right atrium), RV (right ventricle).

Fetal echocardiography revealed no obvious congenial heart anomaly.
Prophylaxis for bacterial endocarditis was given to the patient. The intrapartum period was uneventful. Patient had a vaginal delivery of a term, healthy male baby of wt $3 \mathrm{~kg}$. Outlet forceps were applied to cut short the second stage of labor. Post partum period was uneventful. She was given low molecular weight heparin for the prophylaxis of paradoxical embolism and was discharged on 4th postnatal day in satisfactory condition.

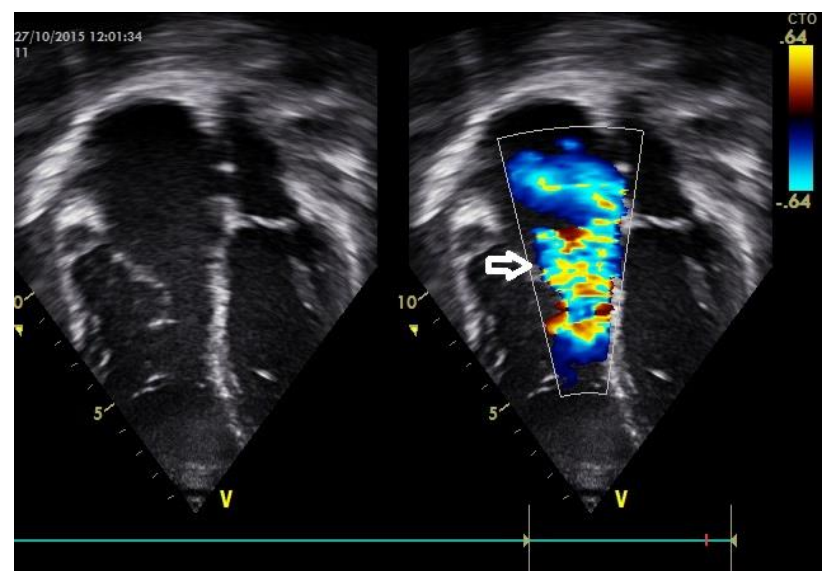

Figure 3: Echocardiography: Four chamber view. Color flow showing moderate TR.

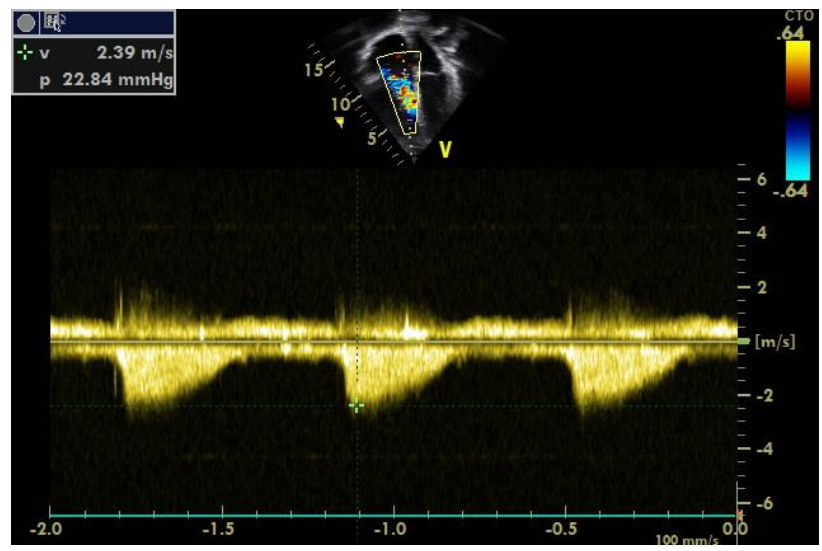

Figure 4: Echocardiography: Continuous wave Doppler. Low pressure TR. $\mathbf{P}$ (peak gradient $)=\mathbf{2 2 . 8 4}$ mmHg.

\section{DISCUSSION}

EA is a rare malformation of the tricuspid valve, characterized by adherence of the septal and posterior leaflets of tricuspid valve to the underlying myocardium, apical displacement of the functional annulus $>8 \mathrm{~mm} / \mathrm{m} 2$ body surface area, dilation of the atrialized portion of the $\mathrm{RV}$, tethering of the anterior leaflet and dilation of the right atrio-ventricular junction. An inter-atrial communication (Atrial Septal Defect or Patent Foramen Ovale) is present in $80-94 \%$ of patients of EA. Accessory pathways (Wolff-Parkinson-White syndrome) are commonly associated with EA (6-36\%) and may lead to supra-ventricular tachycardia. First degree heart block is 
found in 50\% of patients (may relate to right atrial dilatation and stretch). ${ }^{3}$ Our patient did not have any signs of pre-excitation.

In pregnancy, several physiological changes occur within the cardiovascular system. Plasma volume increases with a smaller rise in red cell mass. Cardiac output rises by $40 \%$ with an increase in both stroke volume and heart rate and with an accompanying rise in circulating catecholamines. Systemic blood pressure is lower than in non pregnant state indicating a considerable reduction in peripheral vascular resistance and placental shunting. ${ }^{4}$

In patients with Ebstein's anomaly these physiological changes may have appreciable adverse hemodynamic consequences. In the presence of impaired right ventricular size and function, increased blood volume may be poorly tolerated and result in worsening of tricuspid incompetence, raised right atrial pressure and increased right to left shunting. ${ }^{5}$

EA may manifest clinically at any age and has a highly variable clinical course. Adults often present with cyanosis, dyspnoea, palpitations, decreasing exercise tolerance and fatigue. ${ }^{6}$ In the presence of an inter-atrial communication the risk of paradoxical embolization, brain abscess and sudden cardiac death increases. But if the shunt is insignificant as it was in our case, the risks are less.

This anomaly does not have any effect on fertility, even in women with cyanosis. ${ }^{6}$ According to the current guidelines, women with EA without cyanosis and heart failure are encountered to World Health Organization (WHO) risk class II and usually tolerate pregnancy well. ${ }^{7}$ In contrast, symptomatic patients with cyanosis and/or heart failure should be treated before pregnancy or counseled against pregnancy. During pregnancy, the patient should be monitored by regular echocardiography and the probability of maternal and neonatal events may be predicted from the baseline characteristics of the mother. ${ }^{8}$ One should not forget that heart failure, stroke, arrhythmias and paradoxical embolism can occur even in the asymptomatic patients.

While pregnant patients with EA are usually acyanotic, those with inter-atrial shunting can develop shunt reversal and cyanosis in pregnancy. These are related to increased fetal loss rate, increased premature deliveries, and low birth weight and thromboembolic complications.

Connolly and Warnes, reported the outcome of 111 pregnancies in 44 women with EA. In this report 16 patients were cyanotic, 20 had an inter-atrial communication (ASD/PFO). Majority (76\%) of pregnancies resulted in live birth, $89 \%$ were delivered vaginally, $11 \%$ by caesarean section. The mean birth weight of infants born to cyanotic women was significantly lower than of newborns of acyanotic women (2530 gms vs. 3140 gms, $p<0.001){ }^{6}$ In our patient there was no cyanosis; she delivered at term, an average for gestational age baby.

The preferred mode of delivery is vaginal in almost all cases. ${ }^{4}$ The management during labor should avoid all factors leading to congestive heart failure, cyanosis and arrhythmias. ${ }^{8,9}$ To maintain normal sinus rhythm during labor, adequate pain relief in the form of epidural analgesia is helpful and can be upgraded to anaesthesia if caesarean section is indicated. ${ }^{5}$ During the second stage of labor, Valsalva maneuver causes an increase in intrathoracic pressure, increase in right to left shunt, therefore assisted vaginal delivery is indicated., 6 Endocarditis prophylaxis in the peripartum period is not indicated for the pregnant with EA. ${ }^{10}$ However we gave that to our patient.

The risk of congenital heart disease in offspring is reported in $4-6 \%$, and familial EA in $0.6 \%{ }^{6}$

\section{CONCLUSIONS}

Pregnancy is well tolerated in the absence of severe maternal cardiomegaly, cyanosis and arrhythmias and in those with mild cardiac dysfunction as evaluated at echocardiography and a low NYHA class. However EA may present with a multitude of problems and hence should be considered as high risk and cared for in a tertiary centre by a multidisciplinary team involving a pediatric cardiologist, obstetrician and anaesthetist.

\section{Funding: No funding sources \\ Conflict of interest: None declared \\ Ethical approval: Not required}

\section{REFERENCES}

1. Paranon S, Acar P. Congenital heart disease: Ebstein's anomaly of the tricuspid valve: from fetus to adult. Heart. 2008;94:237-43.

2. Arias F. Fetal dysmorphology. In: Daftari SN, Bhide AG, eds. Practical guide to high risk pregnancy and delivery: A south asian perspective. 3rd ed. New Delhi: Elsevier. 2008:76-7.

3. Leśniak-Sobelga A, Tomkiewicz-Pająk L, Pająk J, Podolec P. Pregnant woman with Ebstein's anomaly. Journal of Rare Cardiovascular Diseases. 2012;15;1(1):13-7.

4. Donnelly JE, Brown JM, Radford DJ. Pregnancy outcome and Ebstein's anomaly. Br Heart J 1991;66:368-71.

5. Chatterjee S, Sengupta I, Mandal R. Anaesthetic management of caesarean section in a patient with Ebstein's anomaly. Indian J Anaesthesia. 2008;52:321-3.

6. Connolly H, Warnes CA. Ebstein's anomaly: outcome of pregnancy. J Am Coll Cardiol 1994;23:1194-8.

7. The Task Force on the Management of Cardiovascular Diseases during Pregnancy of the 
European Society of Cardiology (ESC) et al. ESC Guidelines on the management of cardiovascular diseases during pregnancy. Eur Heart J 2011;32:3147-97.

8. Nataloni M, Mocchegiani R. Ebstein's anomaly and pregnancy: a case report. Ital Heart J. 2004;5(9):70710 .

9. Chopra S, Suri V, Aggarwal N. Ebstein's anomaly in pregnancy: Maternal and neonatal outcomes. J Obstet Gynaecol Res. 2010;36:278-83.

10. Habib G, Hoen B, Tornos P. Guidelines on the prevention, diagnosis, and treatment of infective endocarditis (new version 2009): the Task Force on the Prevention, Diagnosis, and Treatment of Infective Endocarditis of the European Society of Cardiology (ESC). Eur Heart J. 2009;30:2369-413.

Cite this article as: Sharma C, Singh SS, Saha MK, Pegu B. Successful pregnancy in a patient with Ebstein's anomaly: a case report and review of literature. Int J Reprod Contracept Obstet Gynecol 2016:5:903-6. 